\title{
Faktor Pendorong Dan Penarik Penduduk Migran Kota Bekasi Ke Jakarta
}

\author{
Push and Pull Factors Bekasi City's Migrant Peoples to Jakarta
}

\author{
Subhan Adi A, Nanik Istiyani ${ }^{1}$, Andjar Widjajanti \\ Jurusan Ekonomi Pembangunan, Fakultas Ekonomi dan Bisnis, Universitas Jember \\ Jln. Kalimantan 37, Jember 68121 \\ E-mail: istiyanife@gmail.com
}

\begin{abstract}
Abstrak
Penelitian ini bertujuan untuk mengidentifikasi faktor pendorong dan pernarik penduduk migran Kota Bekasi Ke Jakarta dengan pendekatan kualitatif. Populasi dalam penelitian ini merupakan seluruh penduduk migran Kota Bekasi dan mereka yang melakukan mobilitas sekuler/commuter sebagai sampel. Metode analisis yang digunakan dalam penelitian ini adalah kualitatif deskriptif. Hasil dari penelitian ini adalah: (1) faktor pendorong penduduk migran kota Bekasi ke Jakarta terdiri dari pendidikan, ekonomi, dan transportasi; dan (2) faktor penariknya adalah pendidikan, ekonomi (adanya kesempatan kerja dan tingkat pendapatan yang lebih tinggi), kesehatan, dan hiburan.
\end{abstract}

Kata Kunci: Urbanisasi, Mobilitas Penduduk, Penduduk Migran, dan Kualitatif Deskriptif

\begin{abstract}
This study aims to identification factors Bekasi City's migrants peoples to Jakarta. Population in this research was all the migrant peoples in Bekasi City and whose doing sekuler/commuter mobility were the samples. The analytical method used in this research is qualitative descriptive. The results from this study are: (1) push factors that driving migrants to Jakarta Bekasi city are education, economic, and transportation, and (2) its pull factor are education, economy (job oppurtunity and income rate are higher), health, and entertainment.
\end{abstract}

Keywords: Mobility, Urbanitazion, Migrant People and Qualitative Descritive

\section{Pendahuluan}

Perpindahan penduduk (tenaga kerja) merupakan faktor demografi yang ketiga yang memengaruhi pertumbuhan penduduk suatu daerah, selain kelahiran dan kematian. Biasanya perpindahan penduduk tidak begitu berpengaruh terhadap pertumbuhan penduduk suatu daerah, kecuali di daerah tertentu.

Bagi Indonesia mobilitas penduduk mempunyai andil yang sangat besar bagi proses pertumbuhan ekonomi. Di samping itu perkembangan nasional yang terlah dilakukan selama ini, telah memberikan kontribusi kepada perkembangan pola dan arah migrasi penduduk.

Mobilitas penduduk pada awalnya didominasi oleh mobilitas nonpermanen yang merupakan mobilitas jarak pendek dengan waktu relatif lama. Pada tahap selanjutnya, mobilitas permanen yang berkembang. Tetapi, dengan semakin majunya sarana, prasarana transportasi dan komunikasi, pola mobilitas penduduk nonpermanen khususnya olak-alik atau nglaju menunjukkan peningkatan (Sutyastie Seomitro, 1998).

Arus migrasi penduduk juga dipeengaruhi oleh kegiatan ekonomi di suatu wilayah karena alasan utama seseorang untuk pindah adalah alasan ekonomi. Migran pada umumnya menuju ke daerah-daerah yang merupakan pusat-pusat kegiatan ekonomi dan pemerintahan.

Jakarta merupakan salah satu kota tujuan para migran, karena merupakan ibukota Indonesia, pusat pemerintahan dan kegiatan ekonoomi. Para migran mempunyai harapan bahwa hidup di Jakarta akan membawa perubahan dalam kehidupannya, khususnya dalam bidang ekonomi. Dengan anggapan di Jakarta tersedia kesempatan kerja, baik formal maupun informal dengan penghasilan yang lebih tinggi dari daerah asalnya. Namun fenomena yang ada, kepadatan penduduk di Jakarta justru semakin meningkat dan mengakibatkan masalah baru yaitu kurangnya lahan tempat tinggal bagi para migran Jakarta. Akibatnya para migran pindah ke kota sekitar Jakarta yang memungkinkan mereka tetap dapat bekerja di Jakarta.

Bekasi merupakan salah satu kota di dekat Jakarta yang menjadi pilihan para migran sebagai tempat tinggal, karena adanya pemukiman yang layak, nyaman, tersedianya sarana dan prasaran pemukiman, dan perkembangan transportasi yang menghubungkan kota Bekasi dengan Jakarta. Akibat dari itu banyak para pelaku urbanisasi yang lebih memilih kota Bekasi sebagai kota tujuan urbanisasi.

Pada tahun 2015, hampir 53\% dari jumlah penduduk kota Bekasi setiap harinya melakukan aktivitas di Kota Jakarta pada pagi hari dan kembali ke Kota Bekasi di malam harinya. Aktivitas dominan yang umum dilakukan oleh para commuter ini yaitu, bekerja dan sekolah. Aktivitas kaum migran yang melakukan pergerakan dari wilayah pinggiran ke kota induk dapat dikelompokkan sebagai migrasi ulang alik. Migrasi

\section{Coresponding author}


ulak-ulik yaitu pergerakan yang dilakukan oleh migran dengan tidak ada niatan untuk menetap di wilayah tujuan dan dilakukan secara rutin dalam jangka waktu yang pendek dan dapat terjadi dalam satu hari.

Pada penelitian ini yang dijadikan objek penelitian adalah orang yang notabennya bukan orang asli (migran) Kota Bekasi. Permasalahan dalam penelitian ini adalah apa saja faktor pendorong dan faktor penarik sehingga penduduk migran Kota Bekasi ke Jakarta?

Tujuan penelitian ini adalah untuk mengidentifikasi faktor pendorong dan faktor penarik penduduk migran kota Bekasi ke Jakarta.

\section{Metode}

\section{Rancangan Penelitian}

Penelitian ini merupakan peneliatan kualitatif yang menggunakan pendekatan fenomenologis. Objek penelitian ini adalah penduduk migran di Kota Bekasi. Analisis dilakukan secara deskriptif menggunakan data primer dan data sekunder.

\section{Jenis dan Sumber Data}

Jenis data yang digunakan dalam penelitian ini adalah data primer dan data sekunder. Data primer diperoleh langsung dari responden melalui observasi dan wawancara untuk mengetahui identitas responden, seperti: nama, pendidikan, pekerjaan, pendapatan, daerah asal, gambaran umum responden tentang kota Bekasi dan kota Jakarta. Data sekunder yang digunakan dalam penelitian diperoleh dari dokumentasi mengenai jumlah penduduk di Kota Bekasi dan jumlah penduduk ke kota Jakarta.

\section{Populasi dan Sampel}

Populasi pada penelitian ini adalah penduduk migran kota Bekasi yang melakukan mobilitas sekuler ke Jakarta, Pemilihan sampel dalam penelitian ini dilakukan dengan metode snowball sehingga didapatkan jumlah sampel sebanyak 40 orang responden.

\section{Metode Analisis Data}

Penelitian ini menggunakan bentuk metode penelitian deskriptif. Penelitian ini dilakukan di Kota Bekasi yang terdiri dari 4 wilayah yaitu: Bekasi Timur, Bekasi Utara, Bekasi Barat, dan Bekasi Selatan. Waktu penelitian dilaksanakan selama 4 bulan, pada saat berangkat kantor dan pulang kantor.

Teknik pengumpulan data yang digunakan adalah observasi, dan wawancara. Observasi dilakukan pada tempat yang menjadi pintu masuk dan keluar kota Bekasi seperti stasiun, terminal besar, terminal bayangan, jalan raya perbatasan, dan tempat hiburan yang letaknya berada di perbatasan antara kota Bekasi dan Jakarta. Wawancara bebas terpimpin yaitu pelaksanaan secara bebas tetapi berdasarkan pada kerangka yang telah tersusun sebelumnya (melalui kuesioner).

Analisis data dimulai dengan melakukan wawancara mendalam dengan informan. Setelah melakukan wawancara, membuat transkip berdasar kuisioner. Setelah menulis hasil wawancara ke dalam transkip, maka semua data akan dibuat tabel atau grafik yang akan diceritakan hasil dari penelitian tersebut.

\section{Hasil dan Pembahasan}

\section{Identitas Responden}

Responden merupakan pendatang (migran) dan bertempat tinggal di daerah tujuan, yaitu Bekasi. Mereka berasal dari Jawa Tengah (35\%), Jawa Barat (25\%), Jawa Timur (27,5\%), dan Banten (12,5\%).

Responden terdiri dari perempuan sebanyak 13 orang $(32,5 \%)$ dan 27 orang $(67,5 \%)$ adalah laki-laki. Berdasarkan status perkawinan responden terdiri dari: $40 \%$ belum menikah (10 orang laki-laki dan 6 orang perempuan), 57,5\% sudah menikah (17 orang laki-laki dan 6 orang perempuan), dan $2,5 \%$ janda. Responden yang berusia produktif (25-45 tahun) sebanyak 35 orang atau 87,5\%. Responden dengan pendidikan SMA/sederajat sebanyak 37,5\%; D3 sebanyak 17,5\%; S1 sebanyak 42,5\%; dan S2 sebanyak 2,5\%.

Responden yang sudah tinggal di Bekasi selama 16-20 tahun sebanyak $27,5 \%$ (11 orang). Sedangkan responden yang tinggal di Bekasi selama 5-10 tahun berjumlah 25\% (10 orang). Berdasarkan tempat tinggal, responden yang berawal dari Bekasi Selatan sebanyak 35\%, 30\% dari Bekasi Barat, dan masing-masing 17,5\% dari Bekasi Timur dan Bekasi Utara. Responden yang sudah memiliki rumah sendiri sebanyak $55 \%$, masih berada di rumah orang tua/mertua sebanyak 30\% dan kontrak sebanyak 15\%.

Penduduk migran kota Bekasi yang ke Jakarta karena keinginan dirinya sendiri sebanyak $15 \%$, karena faktor keluarga sebanyak $70 \%$, dan ajakan teman sebanyak $15 \%$. Penduduk migran kota Bekasi yang ke Jakarta memiliki tujuan ikut keluarga sebanyak 50\% kemudian karena kerja sebanyak $32,5 \%$, kuliah sebanyak $12,5 \%$, ingin menetap sebanyak 5\% dan ikut suami sebanyak 2,5\%.

Responden yang melakukan mudik pada hari raya, minimal tiap 1 tahun sekali, sebanyak 57,5\% (23 orang). Mayoritas responden memilih menggunakan pesawat, yaitu $30 \%$ dari total responden. Sedangkan sisanya memilih menggunakan transportasi lainnya seperti kereta, mobil pribadi, bus dan motor. Jumlah responden yang menggunakan anggaran untuk mudik sebesar 500rb-1 juta adalah 50\%, kemudian 27,5\% responden menghabiskan biaya di atas 3 juta untuk transportasi mudik.

\section{Faktor Pendorong}

\section{Pendidikan}

Pendidikan dan opini untuk menyekolahkan anak merupakan salah satu faktor penduduk migran kota Bekasi memutuskan untuk ke Jakarta. Hasil penelitian menujukkan pendidikan terakhir para responden di mana $42,5 \%$ adalah lulusan $\mathrm{S} 1$ dan $37,5 \%$ lulusan SMA. Disamping itu responden memiliki keahlian khusus seperti Bahasa Inggris, komputer, dan sebagainya yang dapat digunakan sebagai pendukung untuk mencari pekerjaan. Mayoritas responden yang ingin menyekolahkan anaknya di Jakarta dibandingkan di Bekasi karena menganggap kurangnya fasilitas, baik itu dari tenaga pengajar maupun dari alat penujangnya. Responden yang memilih untuk tetap menyekolahkan anaknya di Bekasi ratarata adalah yang berpengasilan kurang dari 5 juta.

\section{Ekonomi}


Menurut opini para responden, terdapat kekurangan lapangan pekerjaan di Bekasi, selain itu rendahnya tingkat upah minimum reginal (UMR) menjadi salah satu daya dorong yang menyebabkan penduduk migran kota Bekasi ke Jakarta, di mana menurut para responden UMR Bekasi belum merata dalam artian tidak semua perusahaan menetapkan gaji karyawan di atas atau setara UMR Bekasi. Selain itu, sebagain besar responden memilih untuk berbelanja kebutuhan sehari-hari di Jakarta dibandingkan di Bekasi, ini yang menjadi pertanyaan karena menurut hasil observasi, jumlah pasar swalayan dan super market di Bekasi sudah mencukupi tetapi kurang peminatnya. Berdasarkan wawancara, diketahui bahwa mayoritas responden melakukan pembelian kebutuhan sehari-hari setiap satu bulan sekali. Mereka menjadikan belanja setiap bulannya juga sebagai hiburan.

\section{Transportasi}

Hasil dari observasi dan wawancara transportasi juga merupakan faktor pendorong penduduk migran kota Bekasi ke Jakarta. Dari hasil observasi karakteristik, lalu lintas kota Bekasi didominasi oleh kegiatan perdagangan, jasa, pendidikan dan komuter dengan pola pergerakan utama berorientasi ke pusat kota dan menuju ke arah Jakarta pada pagi sampai siang hari dan sebaliknya pada sore hari. Kondisi lalu lintas di Kota Bekasi diwarnai dengan kemacetan yang tinggi terutama pada jam-jam kerja/jam sibuk, karena besarnya arus lalu lintas yang kurang didukung oleh prasarana jalan yang ada. $70 \%$ dari penduduk migran kota Bekasi yang ke Jakarta memilih menggunakan kendaraan pribadi untuk pergi ke kantor. Sedangkan sisanya $22,5 \%$ menggunakan kereta dan 7,5\% menggunakan bus. Menurut mereka, faktor kemacetan menuju Jakarta yang membuat mereka memutuskan menggunakan kendaraan pribadi sebagai transportasi yang digunakan untuk menuju ke Jakarta.

\section{Faktor Penarik}

\section{Pendidikan}

Dari 40 responden, 23 di antaranya mempunyai pendapat akan menyekolahkan anaknya di Jakarta. Berdasaarkan wawancara, responden beranggapan jika kualitas pendidikan di Jakarta lebih baik dibandingkan di Bekasi, hal ini ditunjukkan dari jumlah sekolah di Jakarta mulai tingkat SD, SMP, hingga SMA lebih banyak.

\section{Ekonomi}

Ekonomi merupakan faktor penarik utama yang menyebabkan penduduk migran ke Jakarta. Karena semua responden yang diteliti bekerja di Jakarta, selain pekerjaan dapat dilihat dari pendapatan responden. $80 \%$ pekerjaan penduduk migran kota Bekasi yang ke Jakarta adalah sebagai karyawan, walaupun sebagai karyawan pendapatan responden rata-rata sudah mencapai di atas Rp 5.000.000,- per bulan. Pada saat wawancara para responden hanya menyebutkan sebagai karyawan dan tidak menyebutkan jabatannya. Untuk dokter yang diwawancara keduanya merupakan dokter gigi yang pendapatannya di atas Rp 10.000.000,- per bulan.

Responden yang bekerja sebagai wirausaha antara lain pemilik salon mobil yang penghasilan rata-rata bersihnya Rp10.000.000,- per bulan. Responden lainnya merupakan pemilik toko mebel di daerah Jakarta Timur, menurut keterangannya pengahasilan bersih terendah Rp 25.000.000,per bulan. Responden PNS bekerja di sebuah kedinasan di Jakarta, untuk lainnya adalah kontraktor listrik dan guru honorer. Pendapatan terendah yang diperoleh penduduk migran kota Bekasi ke Jakarta sebesar Rp 2.000.000,- per bulan yang terbesar Rp 25.000.000,- per bulan ini menujukan gaji yang didapat sangat menggiurkan sebagai daya tarik tersendiri.

\section{Kesehatan}

Dari seluruh penduduk migran kota Bekasi yang ke Jakarta, $72,5 \%$ menggunakan rumah sakit yang berada di Jakarta, sedangkan sisanya 27,5\% menggunakan rumah sakit di Bekasi. Pemilihan rumah sakit di Jakarta lebih banyak dibandingkan dengan rumah sakit di Bekasi. Alasan yang paling utama menggunakan rumah sakit di Jakarta karena dekat dengan tempat tinggal (22 orang), kemudian dikarenakan fasilitas yang lengkap (6 orang) dan penanganan yang lebih cepat (1 orang). Sedangkan responden yang menggunakan rumah sakit di Bekasi, seluruhnya beralasan karena lebih dekat dengan tempat tinggal. Faktor perbandingan jumlah rumah sakit yang ada di Jakarta dan di Bekasi menjadi alasan responden memilih rumah sakit di Jakarta atau Bekasi. Dari sumber (data.go.id) terdapat 97 rumah sakit di Jakarta, di antaranya 18 rumah sakit khusus, 9 rumah sakit ibu dan anak, dan sisanya rumah sakit umum. Selain itu, ada beberapa rumah sakit umum yang sudah terkenal dan fasilitas peralatan medisnya lengkap seperti RS. Cipto, RS. Pertamina, dan RS. Islam Jakarta. Menurut klikbekasi.com, hingga akhir tahun 2014, jumlah rumah sakit di Kota Bekasi Baru ada 37 buah, 36 milik swasta dan 1 milik pemerintah daerah yakni RSUD Kota Bekasi, Adapun rincianya, rumah sakit tipe $\mathrm{B}$ sebanyak 6 buah, tipe $\mathrm{C}$ sebanyak 13 buah, tipe D sebanyak 11 buah. Ditambah 5 rumah sakit ibu dan anak, 1 rumah sakit bersalin dan 1 rumah sakit rehabilitasi medik

\section{Hiburan}

90\% dari responden memilih untuk berlibur di Jakarta, sedangkan sisanya 7,5\% di Bekasi dan 2,5\% di Bogor. Jakarta lebih banyak dikunjungi daripada Bekasi dan Bogor dengan alasan untuk mencari kuliner (22 orang), untuk mencari tempat hiburan (12 orang), mall, dan lainnya. Sedangkan Bekasi dikunjungi sebagai daerah wisata untuk mencari kuliner dan mall serta Bogor hanya untuk wisata alam. Penduduk migran kota Bekasi yang ke Jakarta mengalokasin dana untuk wisata rata-rata sebesar Rp 400.000 per bulan, baik di daerah Jakarta, Bekasi maupun Bogor.

\section{Faktor Pendorong}

Faktor pendorong penduduk migran kota Bekasi ke Jakarta antara lain:

a) Pendidikan: Dari Bidang pendidikan di kota Bekasi menurut responden masih kurang, terutama di bidang fasilitas baik infrastruktur maupun pengajar

b) Ekonomi: Dari segi ekonomi untuk kebutuhan sehari-hari masih banyak yang memilih Jakarta dengan alasan lebih lengkap, lapangan kerja di kota Bekasi masih kurang, dan UMR masih belum merata, dalam artian masih banyak gaji yang di bawah UMR. 
c) Transportasi: Transportasi menjadi bidang penting di mana akses dari Bekasi untuk ke Jakarta sudah terdukung dengan baik. Walaupun dari responden memilih kendaraan pribadi untuk menuju ke Jakarta.

Faktor pendorong paling berpengaruh yang membuat penduduk migran kota Bekasi ke Jakarta adalah Transportasi. Walaupun dari hasil wawancara $70 \%$ responden menyatakan menggunakan kendaraan pribadi, namun akses untuk ke Jakarta banyak di tambah lagi saat ini di tambah dengan JORR (Jakarta Outer Ring Road) jalan tol yang menghubungkan Bekasi dengan Jakarta namun tidak melewati pusat kota. Ini di buktikan $50 \%$ atau 20 orang responden bekerja di Jakarta Barat, jarak yang di tempuh lewat JORR sedikit lebih dekat dan cepat.

Hasil tersebut mendukung teori yang di kemukakan oleh Lee (1995) dalam Mantra (2003) berpendapat bahwa "faktor daerah asal adalah faktor terpenting. Di daerah asal seseorang lahir dan hidup sehingga dia tahu benar kondisi daerahnya tersebut".

Hubungan penduduk migran dengan daerah asalnya dikenal sangat erat dan merupakan salah satu ciri fenomena migrasi di negara berkembang hubungan tersebut antara lain diwujudkan dengan pengiriman uang, barang bahkan ide ide pembangunan baik secara langsung maupun tidak langsung. Intensitas hubungan ini antara lain ditentukan oleh jarak, fasilitas transportasi, lama merantau, status perkawinan dan jarak kekeluargaan.

\section{Faktor Penarik}

Berdasarkan hasil dari wawancara yang telah diproses faktor penarik penduduk migran kota Bekasi ke Jakarta adalah:

a) Pendidikan: dari segi kualitas maupun kuantitas Jakarta lebih unggul dibandingkan kota Bekasi. Para responden memilih menyekolahkan anaknya di Jakarta karena kualitas baik dari segi infrastruktur maupun pengajar lebih baik dibandingkan Bekasi.

b) Ekonomi: ketersediaan lapangan pekerjaan menjadi daya tarik utama responden ke Jakarta. Selain itu pendapatan lebih besar menjadi daya tarik berikutnya di mana terlihat dari pendapatan yang dikemukakan responden sebelum dan sesudah bekerja di Jakarta.

c) Kesehatan: penduduk migran kota Bekasi menilai fasilitas yang tersedia di rumah sakit Jakarta lebih lengkap dan merespon dengan cepat

d) Hiburan: untuk melepaskan penat bekerja para penduduk migran kota Bekasi memilih liburan ke Jakarta. Salah satu tujuannya yaitu untuk belanja dan kuliner.

Faktor yang paling berpengaruh adalah faktor ekonomi, yang paling utama semua responden bekerja di Jakarta, dari pendapatan yang didapat para responden, selain itu untuk memenuhi kebutuhan sehari-hari responden lebih memilih membeli di Jakarta. Hasil penelitian ini sesuai dengan teori Lee (1995) tentang daya tarik orang melakukan mobilitas penduduk, faktor-faktor penarik mobilitas penduduk antara lain:

a) Tersedianya lapangan pekerjaan.

b) Kesempatan memeperoleh pendapatan yang tinggi

c) Kesempatan yang lebih tinggi memperoleh pendidikan.

d) Keadaan lingkungan yang menyenangkan.

e) Kemajuan di tempat tujuan

\section{Simpulan}

Faktor pendorong penduduk migran kota Bekasi ke Jakarta antara lain pendidikan, ekonomi, dan transportasi. Faktor pendorong yang paling berpengaruh yaitu dari transportasi yang mendukung penduduk migran untuk melakukan mobilitas ke Jakarta. Faktor penariknya adalah pendidikan, ekonomi, kesehatan, dan hiburan. Faktor ekonomi merupakan faktor utama penduduk migran kota Bekasi ke Jakarta, terutama mengenai lapangan pekerjaan, dan pendapatan yang menjadi daya tarik paling kuat.

\section{Referensi}

Fatchan. 2013. Metode Penelitian Kualitatif

Lee, E.S. 1995. Suatu Teori Migrasi. Seri Terjemahan No. 3 Yogyakarta: Pusat PenelitianStudi Kependudukan Universitas Gajah Mada

Mantra, Ida Bagoes. Agus Joko Pitoyo. 1998. Kumpulan Beberapa Teori Mobilitas Penduduk Buku I. Fakultas Geografi. UGM

Mantra, Ida Bagoes. 2003, Demografi Umum, Pustaka Pelajar, Yogyakarta

Mantra, Ida Bagoes. 1984. Mobilitas Penduduk di Indonesia dan Implikasi Kebijaksanaan. Yogya, Pusat Penelitian Kependudukan.

Soemitro, Sutyastie dan Priyono Tjiptohariyanto. 1998. Pemberdayaan Penduduk Dan Peningkatan Kualitas SDM. Jakarta: PT. Cita Putra Bangsa. 